\title{
Um diálogo entre a Educação Ambiental Crítica e a formação continuada de professores em exercício: Um projeto do PIBID de biologia
}

A dialogue between Critical Environmental Education and ongoing teacher training: A project the PIBID of the biology

Un diálogo entre la Educación Ambiental Crítica y una formación continua de profesores en ejercicio: Un proyecto del PIBID de biología.

Eder Spuri de Paula Licenciado em Biologia, UFLA, Brasil. eder_spuri@hotmail.com

Laise Vieira Gonçalves Mestre em Educação, UFSJ, Brasil. laisebiologa@gmail.com

Marina Battistetti Festozo

Professora Doutora, UFLA, Brasil. mbfestozo@hotmail.com

Antonio Fernandes Nascimento Junior Professor Doutor, UFLA, Brasil. toni_nascimento@yahoo.com.br 


\section{RESUMO}

O diálogo entre educação de qualidade e a formação de professores é fundamental para que alcancemos uma educação transformadora. Assim, o Programa Institucional de Bolsas de Iniciação a Docência (PIBID) de Biologia da Universidade Federal de Lavras (UFLA) surge como uma proposta para formação de professores e um mecanismo de diálogo entre universidade e escola. Desse modo, esse trabalho propõe avaliar um projeto de Educação Ambiental Crítica realizado junto à formação contínua de professores em exercício vinculados ao programa e desenvolvido no ano de 2013 nas escolas públicas do município de Lavras, MG. Após análise, foi possível diagnosticar as diferentes concepções dos professores em relação à Educação Ambiental bem como as dificuldades da inserção da mesma nas escolas. Também foi possível perceber as contribuições do projeto e do PIBID para a formação continuada dos professores permitindo que esses docentes compreendam a importância da formação permanente, das potencialidades de estratégias pedagógicas diferenciadas, e de como a contextualização e interdisciplinaridade podem contribuir no processo de ensino aprendizagem. Além disso, permitiu uma reflexão sobre os trabalhos do PIBID de Biologia nas escolas, compreendendo como o mesmo tem articulado suas ações através dos projetos a fim de aprimorá-las cada vez mais.

PALAVRAS-CHAVE: PIBID. Educação Ambiental. Formação Continuada de Professores.

\section{ABSTRACT}

The dialogue between quality education and teacher training is essential if we are to achieve transformative education. Thus, the Federal University of Lavras (UFLA) Biology Initiatory Scholarship Program (PIBID) is a proposal for teacher training and a mechanism for dialogue between universities and schools. Thus, this work proposes to evaluate a Critical Environmental Education project carried out with the ongoing training of teachers in exercise linked to the program and developed in 2013 in the public schools of the municipality of Lavras, MG. After analysis, it was possible to diagnose the different conceptions of the teachers in relation to Environmental Education as well as the difficulties of the insertion of the same in the schools. It was also possible to perceive the contributions of the project and the PIBID to the continuous formation of teachers, allowing these teachers to understand the importance of ongoing formation, the potentialities of differentiated pedagogical strategies, and how contextualization and interdisciplinarity can contribute to the learning process. In addition, it allowed a reflection on the work of the PIBID of Biology in schools, understanding how it has articulated its actions through the projects in order to improve them more and more.

KEYWORDS: PIBID. Environmental Education. Continuing Teacher Training.

\section{RESUMEN}

El diálogo entre educación de calidad y la formación de profesores es fundamental para que alcancemos una educación transformadora. Así, el Programa Institucional de Becas de Iniciación a la Docencia (PIBID) de Biología de la Universidad Federal de Lavras (UFLA) surge como una propuesta para formación de profesores y un mecanismo de diálogo entre universidad y escuela. De este modo, este trabajo propone evaluar un proyecto de Educación Ambiental Crítica realizado junto a la formación continua de profesores en ejercicio vinculados al programa y desarrollado en el año 2013 en las escuelas públicas del municipio de Lavras, MG. Después del análisis, fue posible diagnosticar las diferentes concepciones de los profesores en relación a la Educación Ambiental así como las dificultades de la inserción de la misma en las escuelas. También fue posible percibir las contribuciones del proyecto y del PIBID para la formación continuada de los profesores permitiendo que esos docentes comprendan la importancia de la formación permanente, de las potencialidades de estrategias pedagógicas diferenciadas, y de cómo la contextualización e interdisciplinariedad pueden contribuir en el proceso de enseñanza aprendizaje. Además, permitió una reflexión sobre los trabajos del PIBID de Biología en las escuelas, comprendiendo cómo el mismo ha articulado sus acciones a través de los proyectos a fin de perfeccionarlas cada vez más.

PALABRAS CLAVE: PIBID. Educación Ambiental. Formación Continua de Profesores. 


\section{INTRODUÇÃO}

A educação ambiental deve estar presente no espaço escolar desde as séries iniciais, para que desde pequenos, os alunos possam refletir acerca das questões socioambientais, sua relação com o ambiente, sendo um processo contínuo de reflexão, conforme descrito pela Política Nacional de Educação Ambiental.

Segundo os autores Loureiro e Cóssio (2007), a inserção da educação Ambiental no espaço escolar tem-se dado com ajuda de discussões e criação de políticas públicas e, no entanto, as diferentes escolas apresentam visões variadas a respeito do que trabalham como Educação Ambiental. Percebe-se nos discursos de algumas instituições uma educação voltada para conscientização, sensibilização do indivíduo, se distanciando de um posicionamento crítico, sugerindo assim que sejam repensados e discutidos os direcionamentos da educação ambiental no espaço escolar.

Os problemas ambientais são resultados da forma como a sociedade estabelece suas relações de poder com o ambiente, a extração de recursos naturais, consumo exagerado, sendo necessário um pensamento crítico a respeito dessas relações. Diante dos avanços científicos e tecnológicos presenciados pela sociedade contemporânea, temos o crescente consumismo e por sua vez o descarte de lixo em proporções gigantescas no ambiente, conferindo uma relação desarmônica do homem com o meio ambiente. Nesse sentido, podemos trabalhar essa temática sob uma perspectiva transversal, proposta nos Parâmetros Curriculares Nacionais (BRASIL, 1998), com o tema Meio Ambiente.

A partir desta perspectiva, os integrantes do Programa Institucional de Bolsas de Iniciação à Docência (PIBID) de Biologia da Universidade Federal de Lavras (UFLA) desenvolveram um projeto no ano de 2013 o qual buscou levar para as escolas participantes questões da temática ambiental que foram trabalhadas com os alunos do ensino fundamental e ensino médio, a Educação Ambiental por meio de um viés crítico (LOUREIRO E LAYRARGUES, 2013) buscando levar alunos e professores a (re)pensar e refletir sobre as problemáticas ambientais, conflitos sociais, consumismo, desenvolvimento da sociedade contemporânea dentre outras questões.

\section{OBJETIVOS}

Esse trabalho se propôs a avaliar o processo de formação continuada de professores a partir do desenvolvimento de um projeto de Educação Ambiental Crítica realizado pelo PIBID de Biologia no ano de 2013 nas escolas públicas do município de Lavras, MG vinculadas ao programa.

\section{METODOLOGIA}

Este trabalho se insere no campo das pesquisas qualitativas. A abordagem qualitativa é um método de investigação científica que se preocupa com o porquê de determinados fenômenos, não apenas com a quantificação de dados, mas sim com sua realidade social (MINAYO, 2001). Essa abordagem nos permite compreender as sutilezas dos fenômenos 
estudados, incluindo aqui aqueles que se dão na esfera da educação e da pesquisa desta (SOUZA et al, 2011).

Para analisar as falas foi utilizado o método de categorização, que é uma análise derivada da análise de conteúdo, conforme apresentada por Minayo (2000). A análise de conteúdo busca, a partir do objeto de estudo, colocar maior significação ao que foi relatado e, desse modo, interpretar de forma fiel a ideia central e real dessas falas, como apontado por Mozzato e Grzybovski (2011). Conforme Moraes (1999), a análise de conteúdo nos possibilita ir além das dúvidas, aprimorando e enriquecendo a análise dos dados coletados, compreendendo o que foi relatado de forma mais crítica. As categorias nos permitem encontrar elementos em comum presente no objeto de estudo e a sua inter-relação de ideias e significados, permitindo uma maior compreensão dos dados e da própria análise, o que na prática significa compreender o próprio fenômeno.

Vale destacar que neste estudo foi utilizado a Análise de Conteúdos e a categorização com o objetivo de compreender as ideias contidas nas falas, podendo assim realizar inferências sobre o projeto desenvolvido pelo PIBID e as possíveis contribuições no processo de formação continuada dos professores em exercício.

\subsection{0 desenvolvimento}

Nos momentos de preparação do projeto foram realizadas discussões referentes às questões ambientais a serem abordadas nas escolas buscando uma prática contextualizadora que permitisse aos alunos observarem sua realidade e se sentirem parte integrante da mesma. Desse modo, a atividade buscou se distanciar dos métodos tradicionais de ensino, utilizando ferramentas pedagógicas diferenciadas como celular e redes sociais, colocando o aluno como sujeito ativo no processo de ensino-aprendizagem e permitindo ao mesmo refletir sobre suas ações e relações com a sociedade. Durante as reuniões de construção e preparação para o projeto, foram pensadas as maneiras possíveis para abordar a reutilização do lixo reciclável sendo proposto para os alunos que olhassem para sua realidade e buscassem diagnosticar de forma crítica o que percebiam em relação à problemática ambiental. Esse olhar para a realidade deveria dar-se nos diferentes contextos e espaços em que os alunos habitam e desempenham suas relações sociais, indo desde sua casa até a escola em que estudam. Durante esse processo os alunos fizeram registros por meio de fotografias.

Diante dessa proposta, surgiu a ideia de trabalhar não apenas com uso de imagens e celular como também com as redes sociais, que diante dos avanços tecnológicos e desenvolvimento da sociedade estão cada vez mais presentes no cotidiano dos alunos, podendo se configurar também como ferramenta para aprendizagem, uma vez que oferecem de forma prática e rápida informações de diferentes fontes. Para isso foi criada uma página do PIBID de Biologia, na rede social Facebook, onde os alunos enviaram as fotografias que foram selecionadas e levadas para a sala de aula a fim de subsidiar os diálogos dos bolsistas com os alunos.

Após o planejamento e preparação de atividades formativas como palestras, minicursos e oficinas para os bolsistas e professores, o projeto foi desenvolvido em dois momentos. 0 público alvo foram alunos do segundo ano do Ensino Médio e do sétimo ano do Ensino Fundamental das escolas: Estadual Cristiano de Souza, Estadual Firmino Costa, Estadual João Batista Hermeto, Estadual Cinira de Carvalho e Municipal Professor José Luiz de Mesquita. 
Num primeiro momento os bolsistas do PIBID estiveram nas escolas para um diálogo com os alunos, a fim de diagnosticar as concepções dos mesmos em relação ao meio ambiente e as problemáticas ambientais. Foi solicitado aos alunos que fotografassem no seu cotidiano o que eles compreendiam por "meio ambiente" e "impactos ambientais". Foi pedido que na medida em que registrassem estes momentos, as fotos fossem postadas na página do PIBID para que os bolsistas selecionassem algumas delas para serem utilizadas posteriormente.

No segundo momento os bolsistas retornaram às escolas com as fotografias que foram selecionadas. Através das imagens foram realizados questionamentos e problematizações, levando os alunos a pensar e refletir sobre os problemas e impactos ambientais decorrentes da relação do homem com o meio ambiente. Nesse sentido buscou-se construir com os alunos uma visão crítica e reflexiva da problemática ambiental, abordando questões históricas, políticas, sociais, econômicas. Com a finalização da atividade foi solicitado aos alunos que avaliassem o projeto desenvolvido, além de realizar apontamento sobre o que eles aprenderam com a prática.

Finalizado o projeto, os bolsistas retornaram às escolas para a exibição de um vídeo criado pelos bolsistas do PIBID. O vídeo continha as fotografias feitas pelos estudantes, além de um roteiro que sintetizava todo o projeto desenvolvido bem como suas intenções e abordagens. $O$ vídeo foi exibido aos professores do ensino médio e ensino fundamental das escolas vinculadas ao programa durante as reuniões de módulo e posteriormente foi realizada uma discussão com os professores sobre a atividade desenvolvida e o conteúdo apresentado no vídeo. A discussão foi gravada, as falas dos professores, transcritas e utilizadas para análise.

$\mathrm{Na}$ primeira etapa da análise, foi realizada a leitura de todas as falas dos professores que participaram da reunião de módulo das cinco escolas participantes do projeto. Após essa leitura inicial, foram identificadas as possíveis categorias e suas respectivas frequências presentes nas falas, de acordo com o referencial teórico adotado. As falas foram organizadas e agrupadas em categorias em função dos elementos em comum e ideias centrais presentes nas mesmas, evidenciando elementos importantes para a análise das possíveis contribuições do projeto para a formação continuada dos professores em exercício. Em seguida foi realizada a segunda parte da análise, a discussão desses dados e o diálogo com o referencial teórico.

Para fins metodológicos as escolas participantes do projeto foram identificadas pelas letras (A, B, C, D e E), onde A - Escola Estadual Cristiano de Souza, B - Escola Estadual Firmino Costa, C Escola Estadual João Batista Hermeto, D - Escola Estadual Cinira de Carvalho, E - Escola Municipal Professor José Luiz de Mesquita. Faz-se aqui uma observação: as escolas foram identificadas por letras diferentes apenas para facilitar o processo de categorização, não tendo como finalidade comparar as falas ou realizar análises entre as mesmas. É interessante destacar que durante o processo de análise alguns trechos das falas dos professores participantes foram utilizados para exemplificar e discutir as categorias. Essas falas foram identificadas pela letra correspondente à sua escola seguido pelo número que identifica cada professor, por exemplo "A1", "B2", etc. 


\section{RESULTADOS}

Por meio das falas dos participantes foram encontradas cinco categorias diferentes, sendo elas: 1 - Visão conservadora de Educação Ambiental; 2 - Reconhecimento de ideias de Educação Ambiental Crítica; 3 - Valorização do PIBID e do projeto desenvolvido; 4 - Linguagem e Metodologias Diferenciadas; 5 - Contextualização e Interdisciplinaridade. As descrições dessas categorias aparecem no quadro abaixo (Quadro A):

\section{Quadro A: Descrição das Categorias}

\begin{tabular}{|c|l|}
\hline $\begin{array}{c}\text { Categorias } \\
\text { Ambiental }\end{array}$ & \multicolumn{1}{c|}{ Descrição } \\
\hline $\begin{array}{c}\text { Reconhecimento de ideias de } \\
\text { Educação Ambiental Crítica } \\
\text { uma visão conservadora de Educação Ambiental. }\end{array}$ & $\begin{array}{l}\text { Nessa categoria temos as falas de participantes que se aproximam } \\
\text { de uma visão mais crítica em relação à Educação Ambiental. }\end{array}$ \\
\hline $\begin{array}{c}\text { Valorização do PIBID e do projeto } \\
\text { desenvolvido }\end{array}$ & $\begin{array}{l}\text { Aqui estão inseridas as falas que valorizam o trabalho realizado } \\
\text { pelo programa bem como o projeto desenvolvido. }\end{array}$ \\
\hline $\begin{array}{c}\text { Linguagem e Metodologias } \\
\text { Diferenciadas }\end{array}$ & $\begin{array}{l}\text { Nessa categoria foram agrupadas as falas que reconhecem as } \\
\text { potencialidades das metodologias diferenciadas no espaço } \\
\text { escolar, bem como a utilização de uma linguagem que aproxime o } \\
\text { aluno ao objeto de estudo (no caso, a que fora utilizada na } \\
\text { realização do projeto). }\end{array}$ \\
\hline $\begin{array}{l}\text { Interdisciplinaridade } \\
\text { Essa categoria reúne falas que reconhecem a importância da } \\
\text { contextualização como forma de aproximar a realidade do aluno } \\
\text { com aquilo que se é estudado e também a interação entre as } \\
\text { diferentes áreas do conhecimento. }\end{array}$ \\
\hline
\end{tabular}

No quadro abaixo (Quadro B) são apresentadas as frequências das categorias identificadas. Foram identificadas cada fala pertencente às diferentes categorias. 


\section{da Alta Paulista}

Quadro B: Frequência das Categorias

\begin{tabular}{|c|c|c|}
\hline Categorias & Frequências & Participantes \\
\hline $\begin{array}{l}\text { Visão conservadora de } \\
\text { Educação Ambiental }\end{array}$ & 59 & $\begin{array}{l}\mathrm{A} 1, \mathrm{~A} 2, \mathrm{~A} 3, \mathrm{~A} 4, \mathrm{~A} 5, \mathrm{~A} 6, \mathrm{~A} 7, \mathrm{~A} 8, \mathrm{~A} 9, \mathrm{~A} 11, \mathrm{~A} 12, \mathrm{~A} 16, \mathrm{~B} 1, \\
\mathrm{~B} 3, \mathrm{~B} 8, \mathrm{~B} 11, \mathrm{~B} 17, \mathrm{~B} 21, \mathrm{~B} 22, \mathrm{~B} 23, \mathrm{~B} 24, \mathrm{~B} 25, \mathrm{~B} 26, \mathrm{~B} 27, \\
\mathrm{C} 2, \mathrm{C} 4, \mathrm{C} 5, \mathrm{C} 6, \mathrm{C} 8, \mathrm{C} 14, \mathrm{C} 15, \mathrm{C} 20, \mathrm{C} 21, \mathrm{C} 22, \mathrm{C} 23, \mathrm{C} 24, \\
\mathrm{C} 25, \mathrm{C} 26, \mathrm{C} 27, \mathrm{C} 29, \mathrm{C} 30, \mathrm{C} 31, \mathrm{C} 33, \mathrm{C} 35, \mathrm{D} 2, \mathrm{D} 7, \mathrm{D} 8, \\
\mathrm{D} 9, \mathrm{D} 10, \mathrm{D} 11, \mathrm{D} 12, \mathrm{E} 1, \mathrm{E} 2, \mathrm{E} 4, \mathrm{E} 5, \mathrm{E} 7, \mathrm{E} 8, \mathrm{E} 9, \mathrm{E} 10 .\end{array}$ \\
\hline $\begin{array}{l}\text { Reconhecimento de ideias } \\
\text { de Educação Ambiental } \\
\text { Crítica }\end{array}$ & 33 & $\begin{array}{l}\mathrm{A} 3, \mathrm{~B} 10, \mathrm{~B} 13, \mathrm{~B} 14, \mathrm{~B} 17, \mathrm{~B} 23, \mathrm{~B} 28, \mathrm{C} 1, \mathrm{C} 2, \mathrm{C} 3, \mathrm{C} 5, \mathrm{C} 6, \mathrm{C} 7, \mathrm{C} 9, \\
\mathrm{C} 12, \mathrm{C} 13, \quad \mathrm{C} 16, \quad \mathrm{C} 17, \quad \mathrm{C} 18, \quad \mathrm{C} 20, \quad \mathrm{C} 21, \\
\mathrm{C} 34, \mathrm{C} 35, \mathrm{D} 1, \mathrm{D} 2, \mathrm{D} 4, \mathrm{D} 7, \mathrm{D} 9, \mathrm{D} 10, \mathrm{E} 3, \mathrm{E} 4, \mathrm{E} 10, \mathrm{E} 12 .\end{array}$ \\
\hline $\begin{array}{l}\text { Valorização do PIBID e do } \\
\text { projeto desenvolvido }\end{array}$ & 20 & $\begin{array}{l}\mathrm{A} 1, \mathrm{~A} 2, \mathrm{~A} 4, \mathrm{~A} 5, \mathrm{~A} 7, \mathrm{~A} 8, \mathrm{~A} 9, \mathrm{~A} 10, \mathrm{~A} 11, \mathrm{~A} 12, \mathrm{~A} 13, \mathrm{~A} 16, \\
\mathrm{~B} 10, \mathrm{~B} 23, \mathrm{C} 9, \mathrm{C} 31, \mathrm{C} 33, \mathrm{D} 1, \mathrm{D} 3, \mathrm{E} 3 .\end{array}$ \\
\hline $\begin{array}{l}\text { Linguagem e Metodologias } \\
\text { diferenciadas }\end{array}$ & 17 & $\begin{array}{l}\mathrm{A4}, \mathrm{A6}, \mathrm{A} 9, \mathrm{~A} 10, \mathrm{~A} 13, \mathrm{~B} 7, \mathrm{~B} 9, \mathrm{~B} 23, \mathrm{C} 8, \mathrm{C} 20, \mathrm{C} 34, \mathrm{C} 35, \\
\mathrm{D} 3, \mathrm{E} 3, \mathrm{E} 4, \mathrm{E} 6, \mathrm{E} 9 .\end{array}$ \\
\hline $\begin{array}{l}\text { Contextualização e } \\
\text { Interdisciplinaridade }\end{array}$ & 10 & $\mathrm{A6}, \mathrm{B} 6, \mathrm{C3}, \mathrm{C} 8, \mathrm{C} 9, \mathrm{C} 10, \mathrm{C} 35, \mathrm{E3}, \mathrm{E} 6, \mathrm{E} 9$. \\
\hline
\end{tabular}

\subsection{Um pouco de discussão}

Após a categorização, foram selecionadas algumas falas dos participantes que melhor representam as categorias encontradas buscando discutir de maneira mais significativa os dados coletados durante a análise. Foram analisadas as falas de cento e três (103) professores. A primeira categoria 'Visão conservadora de Educação Ambiental'" possui a maior frequência e nessa categoria estão reunidas as falas dos participantes que em quase ou na totalidade demonstram possuir uma ideia de Educação Ambiental Conservadora, sendo essa ideia bastante recorrente nos espaços escolares e atividades desenvolvidas por professores de diferentes áreas. Conforme apresentada por Loureiro e Layrargues (2013), a educação ambiental possui macrotendências em seu cenário atual, sendo uma delas a conservacionista, ou o que se pode chamar de conservadora. Para os autores essa macrotendência se caracteriza por ações marcadas pelo âmbito individual, onde o sujeito por meio de suas ações individuais busca a mudança em relação à forma como se relaciona com o ambiente, não trazendo em si questões sociais, políticas, históricas e todas as suas dimensões, sendo abordada de forma conteudista, fragmentada e instrumental. Essa tendência é marcada sobretudo pelo descolamento ou afastamento das questões ambientais das questões sociais, de modo geral, da sociedade, é encarada como algo em separado, ou seja, não reconhece a questão ambiental como algo sistêmico. Essas ideias podem ser observadas nas falas de alguns participantes, como em A12, B8, C28, D2, D8: 
A12 - “[...] Nas minhas aulas eu faço isso. Se eu vejo alguém jogando papel no chão eu peço para catar, colocar no lixo $[\ldots]$ ".

B8 - "[...] Eu separo o lixo e faço a minha parte, se a coleta vem ou não, eu faço a minha parte".

C28 - "Eu acho que estes projetos para limpeza do meio ambiente, o caminho é este mesmo".

D2 - "[...] Acho que as empresas tinham que ser responsáveis pelas suas embalagens, e deviam recolher todas as embalagens".

D8 - “[...] eu coloco meu lixo pra fora, está limpo o meu espaço e pronto".

De acordo com Jacobi (2005), essa perspectiva de Educação Ambiental é sedimentada e implica em ações pontuais, sem uma práxis reflexiva. Traz consigo uma abordagem descontextualizada da temática ambiental, desvinculando os problemas sociais dos ambientais, não problematizando assim o sistema e organização de sociedade vigente. Conforme apresenta Loureiro e Layrargues (2013) para que se configure em uma mudança no pensamento e criação de uma sociedade transformadora é necessária uma abordagem que questione as relações políticas, econômicas, sociais não buscando apenas mudanças de valores e costumes, mas sim o surgimento de uma nova sociedade, de uma nova ética.

Ainda nessa categoria, encontramos outro elemento no cenário de uma Educação Ambiental conservadora como podem ser observados nas falas de B3, D5, E2, E4. Essas falas trazem a temática da reciclagem em seu sentido estreito e esvaziado de significado como um mecanismo para solução dos problemas ambientais, não realizando uma abordagem problematizadora e reflexiva. Algumas das falas inclusive, como B3, reforçam a ideia de que as ações individuais são suficientes para enfrentar as questões ambientais.

B3 - "Há três anos trabalhamos esta temática. Nós vimos muitos problemas e não soluções. Tá na hora de encontrar caminhos para reciclar. Eu estava conversando com a minha vizinha e ela citou várias ações de antigamente como, por exemplo, o uso de saquinhos de papéis na compra do pão ao invés de sacolinhas, entre outras. É preciso trabalhar em cima disso".

D5 - "Pouca gente ainda vê lucro do lixo. Se tivesse outra visão do lixo. Já que o mundo é capitalista, podemos pensar como que este lixo pode render".

E2 - "No caso do lixo foi muito interessante porque a gente tem que sempre estar trabalhando com isto, o que fazer com o lixo, a reciclagem".

E4 - "Achei interessante a participação dos alunos em tirar fotos e ver o meio em que está a sociedade, através da sociedade com o meio ambiente. Acho interessante trabalhar com eles em recolher estes lixos, trabalhar um pouco de reciclagem com eles."

De acordo com Layrargues (2002), frente aos problemas ambientais temos a constante presença do lixo, sendo resultado de uma massiva produção do modelo capitalista e estruturação vigente da sociedade. Isso fez com que políticas de combate a esse crescente problema fossem debatidas e consequentemente levadas para o espaço escolar sendo trabalhado por meio da educação ambiental. Essas concepções apontadas pelo autor aparecem de modo recorrente nas falas dos professores onde a questão do lixo aparece descolada do modelo de produção.

Por meio das falas analisadas percebemos elementos que sinalizam a ausência da problematização e reflexão sobre os temas apontados, como o do lixo, demonstrando a 
prevalência de uma ideia conservadora da educação ambiental. Foi possível perceber que a temática é abordada em salas de aula pautada na mudança comportamental ao invés de refinamento cultural e do pensamento, não utilizando, por exemplo, o processo de coleta seletiva e reciclagem como um tema gerador para discussões a respeito da temática ambiental.

Outro aspecto a ser destacado nessa categoria, foi referente ao recorrente uso da palavra/termo "conscientização" pelos participantes. As falas apontam para a "necessidade de conscientização" do sujeito como observamos em A1, A8, A9, B21, C15, C24, C25 e E7.

A1 - “Um avanço para conscientização dos alunos. Foi um ótimo trabalho. Todo ano a gente tenta fazer um trabalho deste de conscientização dos alunos, para cada ano estar cuidando mais do nosso ambiente".

A8 - "Queria parabenizar, achei o trabalho muito importante. Acho que conscientização é o principal caminho [...]".

A9 - "[...] é muito importante conscientizar. Ver que precisa cuidar da sala. [...]".

B21 -“O trabalho de recolhimento do lixo é feito, só que a conscientização não chega a ser consolidada $[\ldots] "$.

C15 - "Sou da área de biologia e inclusive tenho projetos de educação ambiental. Há 12 anos eu não vejo muitas mudanças na nossa região. O trabalho de conscientização tem que ser contínuo".

C24 - "É preciso conscientizar a população (...). Essa conscientização tem que vir desde pequeno mesmo $[\ldots] "$.

C25 - "Eu acho realmente que a questão é de conscientização".

E7 - "Acho que o trabalho de conscientização do meio ambiente, do lixo, da reciclagem é um trabalho árduo e incansável. E a gente não pode desistir nunca, tem que estar sempre batendo na mesma tecla, principalmente nos primeiros anos".

Essa preocupação manifestada pelos professores em "conscientizar os alunos" reflete a maneira como o tema meio ambiente foi incorporado na educação formal. De acordo com Leff (2005 apud Leite e Rodrigues, 2011) essa incorporação limitou-se a trabalhar a internalização de valores de conservação da natureza destacando apenas os problemas mais visíveis, como a questão do lixo, que é recorrente na fala dos professores. Desse modo, a temática reduziu-se a internalização de "uma consciência ecológica" pelos alunos. De acordo com Tozoni-Reis (2006) muitas propostas educativas que indicam a conscientização estão distantes do significado que explicam o termo, que é a construção crítica da leitura de mundo, a capacidade de superação da consciência ingênua. A autora ainda ressalta que a conscientização como princípio da educação ambiental "não é um resultado imediato da aquisição de conhecimentos sobre os processos naturais, mas a reflexão filosófica e política, carregada de escolhas históricas que resultam na busca de uma sociedade sustentável (IDEM, p. 106)". Assim, é possível perceber através das falas que os professores usam o termo "conscientização" como uma forma repetida de se discutir ou pensar a educação ambiental, mas não demonstram compreender de fato a dimensão crítica de tal termo.

É necessário destacar ainda aquela no que talvez seja a questão mais espinhosa dessa categoria: a manutenção da concepção de educação ambiental conservadora dos professores 
mesmo depois de terem contato com a perspectiva crítica, sobretudo na realização do projeto. Essa é uma questão que nas falas aparece de modo numeroso e recorrente. Em suas falas, a muitos dos professores demonstraram manter essa visão conservadora. Nesse sentido, talvez a concepção de Oliveira (2015) nos sirva como um direcionamento diante desta questão, quando a autora aponta que os professores têm uma resistência em assumirem integralmente novas posturas, uma vez que por terem ficado presos ao modelo tradicional e fragmentador de ensino, têm dificuldade em repensar novos caminhos e concepções para a sua prática.

Na segunda categoria aqui apresentada 'Reconhecimento de ideias de Educação Ambiental Crítica' temos as falas dos participantes que após a exibição do vídeo com a apresentação do projeto realizado, mesmo mantendo em seus discursos, vestígios do que abordamos/consideramos como educação ambiental conservadora, eles conseguem avançar um pouco mais do que os demais, demonstrando ter conseguido visualizar aspectos mais críticos no que se refere à temática ambiental. Algumas falas destacam aspectos sociais e econômicos, reconhecem a importância destas dimensões no contexto de Educação Ambiental, apontando também o modelo de produção, o capitalismo e o consumismo. Tais ideias podem ser observadas nas falas de A3, B10, B28, C5, C7, C9 e E3:

A3 - "O aspecto social e econômico eu achei importante. (...) Os alunos estão inseridos no consumismo, a mídia influenciando o meio ambiente. A casa, a escola é o meio ambiente deles. Eles acham que a escola é diferente da casa deles. A gente tem que trabalhar muito neste sentido".

B10 - "[...] Trabalhei com eles a questão das desigualdades sociais e perguntei para eles se tinha relação com as questões ambientais".

B28 - [...] "Acho fundamental se trabalhar estas questões (sociais) aqui dentro da escola. O meio ambiente não se resume apenas à questão ecológica. Isso que nós temos aqui é o nosso meio ambiente, não tem árvore, não tem nada, mas é o espaço que a gente convive" [...].

C5 - "Uma questão que me chamou a atenção foi a questão do capital, o consumo e a poluição (...)".

C7 - "A lógica da produção e exploração precisa estar inserida neste processo, assim como a reprodução deste sistema, para poder despertar uma consciência ambiental. Podemos tentar construir esta contradição da sociedade e do modelo".

C9 -“(...) Foi importante relacionar a tecnologia com os problemas ambientais e sociais".

E3 - [...]"Outra coisa que me chamou atenção foi este intercâmbio entre o social e o ambiental, porque as pessoas tem mania de separar social de um lado e ambiental de outro. (...) E essa junção do social e ambiental foi muito interessante na proposta".

Algumas falas relatam a questão do consumismo, assim como o papel da mídia como mecanismo de aproximação entre o sujeito e aquilo que é produzido induzindo consumo e alimentando a máquina do capitalismo. As falas também apontam para a conscientização do indivíduo no sentido de se questionar as reais necessidades de ser ter e adquirir determinados bens, contribuindo para problemática ambiental.

Na busca por uma educação que esteja comprometida com a crítica, com a autonomia de seus educandos, é imprescindível uma abordagem que permita ao aluno pensar, argumentar, discutir e agir de modo transformador na sociedade. Assim é importante que o professor esteja em constante processo de formação, promovendo um ensino plural e não excludente 
das questões sociais, ambientais, históricas, políticas, econômicas. Nesse contexto, Diório e Rôças (2013) nos trazem os aspectos da alfabetização científica bem como um olhar crítico para a mídia afim de que o indivíduo não se torne apenas um espectador passivo daquilo que Ihe é apresentado, trazendo assim questionamentos e reflexões da e para a realidade social.

A terceira categoria apresentada 'Valorização do PIBID e do projeto desenvolvido' faz menção ao PIBID e ao projeto, reconhecendo e valorizando o programa no espaço escolar percebendo e destacando as contribuições das atividades desenvolvidas. As falam também sugerem a necessidade de que o programa e suas atividades estejam em contato contínuo com a escola, e também relatos de reflexão pessoal e profissional. Podemos ver esses apontamentos nas falas de A4, A10, A11, A13:

A4 - [...] E quando o pessoal do PIBID veio aqui e trouxe esta proposta de atividade já abriu um pouco a consciência dos nossos alunos sobre o que é meio ambiente, sobre qual a maneira de se trabalhar o meio ambiente [...]

A10 - "Eu estava lá na sala 2002 quando os alunos realizaram a atividade e assisti. Percebi que os alunos gostaram muito e participaram. Todo mundo querendo falar primeiro que o outro. Então vi que eles gostaram mesmo. As vezes poderiam dizer 'Ah, mas estão falando disso de novo?" Mas não, a maneira como que eles trouxeram para os meninos, eles adoraram. Então acho que foi muito bom, que foi muito válido".

A11 - "Queria agradecer pelo fato da nossa escola estar vinculada a uma universidade como a UFLA e pedir que vocês possam estar sempre aqui conosco. (...)".

A13 - "Como professora das series iniciais posso dizer que é muito importante o que vocês estão fazendo e passando para nós este caminho [...]".

A existência de uma educação de qualidade e transformadora está intimamente ligada ao processo de formação de professores, seja ela inicial ou continuada. Conforme Ferreira e colaboradores (2015), temos a criação de políticas públicas para que seja possível essa educação emancipadora e a superação das falhas no processo de formação docente, bem como o aperfeiçoamento e construção da identidade como professor. Nesse contexto temos o PIBID e suas potencialidades para a formação docente, como pode-se perceber pelos relatos dos professores da escola.

No atual cenário de desvalorização da carreira docente, dificuldades e necessidades de um sistema público de ensino de qualidade e acessível a todos temos também associado a isso a pouca experiência didática nos processos de ensino-aprendizagem, nas noções das relações que se configuram o ambiente escolar (RAUSCH \& FRANZ, 2013).

Rosa e Mattos (2013) trazem a ideia da continuidade do aprender relacionado ao desenvolvimento docente, onde essa prática é constante nos dando a ideia de tempo e espaço. Assim, a formação de professores não se limita ao contexto da universidade, sendo também possibilitado por programas como o PIBID e sua continuação no exercício profissional. Na quarta categoria 'Linguagem e Metodologias diferenciadas' temos as falas que reconhecem as potencialidades das metodologias diferenciadas no espaço escolar, bem como a utilização de uma linguagem que aproxime o aluno ao objeto de estudo. Essas ideias podem ser percebidas nas falas de A4, A9, A13, B9, D3. 
A4 - "[...] o pessoal traz para nós aqui da escola uma linguagem jovem, eficaz, um pouco mais claro de se entender (...)".

A9 -“[...] eles gostam muito quando a gente faz trabalhos diferentes com eles."[...]

A13 - “[...] hoje não existe mais o ensino de biologia no papel. (...) os alunos se sentem valorizados nestas atividades.[...]"

B9 - "O que eu achei interessante foi o uso do audiovisual, pois a atenção se volta para a atividade, se fosse uma cartilha o aluno iria guardar na mochila e não seria tão eficaz".

D3 - “(...) Os alunos se interessam muito porque eles vão sair de sala, vão tirar fotos”.

Conforme Moreira (2015), diante do manancial de informações e conteúdos presentes em nossa sociedade, sua expansão e suas diferentes formas de se relacionar, é preciso que o professor esteja apto para sistematizar essas informações, conhecimentos de forma que em sala de aula sua prática seja abrangente, transformadora, comprometida com a formação social. Para que essa prática cumpra seus objetivos, o professor possui um importante papel em compreender seu espaço de trabalho, a pluralidade de sujeitos, crenças, culturas e valores que ali existem e assim pensar, elaborar, construir atividades pedagógicas que considerem os diversos agentes e sua realidade, tendo como pressuposto um método dialógico. Dessa forma, é importante que o professor esteja em contínua formação, a fim de mudar essa realidade. De acordo com Ferreira e colaboradores (2015), diante da relação do PIBID com as escolas, os professores possuem a oportunidade por meio do diálogo e troca de experiências de se reinventar, refletir sobre a sua prática. Assim, através das atividades desenvolvidas pelo programa, como os que são feitos pelo PIBID Biologia UFLA, podem ainda continuar a aprender e se desenvolver enquanto profissional, participando efetivamente de espaços de formação, levando para a sala de aula uma nova perspectiva de ensino acompanhada de atividades diferenciadas, com linguagem que atraia e desperte o encantamento em seus alunos.

Aqui destacamos também as potencialidades de estratégias pedagógicas que utilizem os celulares, imagens e as redes sociais, conforme utilizado pelo PIBID de Biologia nesse projeto. De acordo com Spuri e Nascimento Júnior (2014), a Educação Ambiental assim como diversas outras áreas podem utilizar de ferramentas pedagógicas que instiguem a participação do aluno em sala de aula, que promovam o encantamento e que despertem o olhar crítico dos mesmos proporcionando o diálogo, a troca de experiências e construção coletiva do conhecimento.

Vivian e Pauly (2012) nos trazem que diante das críticas em relação ao uso de aparelhos celulares dentro da instituição escolar, o mesmo pode ser utilizado no processo de ensinoaprendizagem, sendo um mecanismo tecnológico que pode se prestar a informar e formar os sujeitos. Diante desse fato e de uma sociedade globalizada, altamente tecnológica é preciso que os professores estejam também em formação constante, atualizados e que tenham conhecimento sobre o instrumento que utilizam em sua prática pedagógica, fazendo o uso responsável e aproveitando para estimular os alunos a se questionarem e refletirem sobre as reais necessidades diante do mercado capitalista.

A quinta e última categoria analisada 'Contextualização e Interdisciplinaridade' reúne falas que nos direcionam para a importância da contextualização como forma de aproximar a realidade 
do aluno com aquilo que é estudado e também a interação entre as diferentes áreas do conhecimento. Essas ideias podem ser observadas nas falas de A6, B6, C9, C10, E3, E6, E9.

A6 - “(...) o que destaca é a sensibilização do aluno e trazendo a realidade deles mais próximo a sensibilização é maior, e foi o que foi feito através das fotos tiradas pelos alunos".

B6 - "Sou professora de química e cedi as minhas aulas para a realização das atividades do PIBID com os alunos. Na minha próxima aula eu aproveitei a atividade e pedi que os alunos me relatassem o que havia de química na atividade realizada pelo PIBID e, eles me responderam que não havia nada de química. Aí eu comecei a falar com eles sobre pilhas, baterias e como estes interferem no meio ambiente".

c9 -“(...) Foi importante relacionar a tecnologia com os problemas ambientais e sociais”.

C10 - "Trabalhamos neste bimestre sobre Marx, a alienação, a manipulação da mídia, a relação da moda, a questão do lucro (mais valia) e poderíamos trabalhar juntos."

E3 - [...]"E o que eu vi de mais positivo foi de pedir para eles tirarem fotos, pois eles estão vivenciando o espaço deles. Essa colocação dos professores em conectar as áreas e, que se crie uma conexão é muito importante para que o ensino não fique fragmentado."

E6 - "Achei interessante esta questão das fotos, pois forçou os alunos a prestarem atenção ao redor, aproximando a realidade deles. [...]"

E9 - "Achei interessante vocês levarem os alunos a conhecerem a realidade que eles vivem, tirando as fotos do ambiente que eles vivem".

Muitas vezes, as questões sociais são deixadas de lado nas discussões e diálogos do espaço escolar, o que faz com que o ensino se dê de uma forma descontextualizada da realidade. Conforme argumenta Gonçalves (2013), ao olharmos para nosso contexto histórico, percebemos as desigualdades e conflitos sociais de um povo que não é protagonista de sua própria realidade. E a fim de que esses sujeitos percebam seu papel como agentes de uma sociedade da qual fazem parte e a modificam por meio de suas relações, é necessário que discussões sobre sua cidadania sejam realizadas a fim de se garantir seus direitos e, de modo geral, a formação da sua cidadania.

Dessa forma percebemos que esse tipo de projeto possibilitou a estes professores a percepção de que o ensino deve se dar de forma a contextualizar os conhecimentos, abrangendo o contexto social, histórico, filosófico e político.

Em um relato de uma professora foi possível perceber a possibilidade do trabalho interdisciplinar. No que diz respeito ao diálogo entre as disciplinas Gomes e colaboradores (2015) argumenta que a interdisciplinaridade proporciona um ensino com maior apropriação do objeto de estudo, por trazer consigo variadas vertentes e informações sobre um assunto específico, abordando o mesmo de forma contextualizada. Ainda conforme o PCN, essa perspectiva "busca dar significado ao conhecimento escolar, mediante a contextualização; evita a compartimentalização, mediante a interdisciplinaridade" (BRASIL, 2000, p. 4).

\section{CONCLUSÃO}


O presente trabalho nos permite concluir que o PIBID e seu projeto desenvolvido proporcionou aos docentes em exercício algumas ideias e percepções sobre como a Educação Ambiental pode ser trabalhada em sala de aula sob uma perspectiva transversal e contextualizada aproximando o objeto de estudo ensinado durante as aulas com a realidade de seus alunos. Através das falas dos docentes, pode-se perceber que as atividades realizadas contribuem para uma percepção de que o uso de metodologias e ferramentas pedagógicas possibilitam uma linguagem mais jovem, atual, que pode promover o encantamento dos alunos, instigando os mesmo a participarem. Isso pode levar os professores a perceberem a necessidade de repensar a sua prática na busca de construção de conhecimento significativo.

As análises aqui realizadas nos permitem diagnosticar as diferentes visões sobre a Educação Ambiental por meio das falas, em que grande parte dos professores trazem em seu discurso elementos de uma educação ambiental conservacionista, apoiadas pela mudança comportamental, "conscientização e sensibilização" dos seus alunos. Tal visão persiste mesmo após a realização da atividade sob uma perspectiva crítica, e possivelmente é sustentada diante do fato de que muitas vezes a abordagem da Educação Ambiental nas escolas se dá de forma descontextualizada, pontual. Nesse sentido, se tona fundamental que os professores em exercício estejam em um processo de formação contínua, recebendo apoio e suporte de programas e projetos, como aqui apresentados, para que assim possam superar essa macrotendência de EA, uma vez que ela não nos permite um olhar crítico e reflexivo acerca dos problemas ambientais e sua relação com os conflitos sociais, o contexto histórico, político, econômico e consequentemente a não efetivação de uma Educação Ambiental transformadora.

\section{AGRADECIMENTOS}

FAPEMIG e CAPES/PIBID

\section{REFERÊNCIAS BIBLIOGRÁFICAS}

BRASIL. Parâmetros Curriculares Nacionais: $3^{\circ}$ e $4^{\circ}$ ciclos: apresentação dos temas transversais. Secretaria de Educação Fundamental. Brasília, DF: MEC/SEF, 1998.

BRASIL. Proposta de Diretrizes para a formação inicial de professores da Educação Básica em Cursos de Nível Superior. Grupo de Trabalho do Ministério da Educação. Brasília, 2000.

DIORIO, A. P. I.; RÔÇAS, G.F. As Mídias como Ferramenta Pedagógica para o Ensino de Ciências: Uma Experiência na Formação de Professores de Nível Médio. Revista Práxis, v. 10, 2013.

FERREIRA, M. T. M. ; REIS NETO, J. A. ; NASCIMENTO JUNIOR, A. F. . O PIBID de Biologia da Universidade Federal de Lavras e sua importância para a formação continuada de professores. Revista Práxis (Online) , v. 6, p. 358-363, 2015. 
GOMES, M. R. L.; FERREIRA, L. N. ; NASCIMENTO JUNIOR, A. F. . A abordagem do conceito unificador energia numa perspectiva interdisciplinar e transversal no ensino de Ciências e Biologia. Revista Práxis (Online), v. IV, p. 243-248, 2015.

GONÇALVES, L. V. Uma Perspectiva de Contextualização e Transversalidade na Formação de Professores: O PIBID de Biologia da Universidade Federal de Lavras, MG. 2013. 52 f. Monografia Curso de Licenciatura em Ciências Biológicas, Universidade Federal de Lavras, Minas Gerais, 2013.

JACOBI, P. R. Educação Ambiental: o desafio da construção de um pensamento crítico, complexo e reflexivo. Educação e Pesquisa, São Paulo, v. 31, n. 2, p. 233-250, 2005.

LAYRARGUES, P. P. O cinismo da reciclagem: o significado ideológico da reciclagem da lata de alumínio e suas implicações para a educação ambiental. In: LOUREIRO, C. F. B.; LAYRARGUES, P. P.; CASTRO, R. S. (orgs.). Educação Ambiental: repensando o espaço da cidadania. São Paulo: Cortez, 2002.

LEITE, R. F.; RODRIGUES, M. A. Educação ambiental: reflexões sobre a prática de um grupo de professores de química. Ciência e Educação (UNESP. Impresso), v. 17, p. 145-161, 2011.

LOUREIRO, C. F. B.; COSSIO, M. F. B. Um olhar sobre a educação ambiental nas escolas: considerações iniciais sobre os resultados do projeto. In: Mello, S.; Trajber, R.(Org.). Vamos cuidar do Brasil: conceitos e práticas em educação ambiental. MEC/UNESCO, 2007, p. 57-64.

LOUREIRO, C. F. B.; LAYRARGUES, P. P. Ecologia política, justiça e educação ambiental crítica: perspectivas de aliança contra-hegemônica. Trabalho, educação e saúde. v. 11, n. 1, 2013 .

MINAYO, M. C. de S. O Desafio do Conhecimento: Pesquisa Qualitativa em Saúde. 7. ed. São Paulo: Hucitec, 2000. 269 p.

MINAYO, M. C. S. Pesquisa social: teoria, método e criatividade. Petrópolis: Vozes, 2001.

MORAES, R. Análise de conteúdo. Revista Educação, Porto Alegre, v. 22, n. 37, p. 7-32, 1999.

MOREIRA, A. E. C.. O papel docente na seleção das estratégias de ensino. In: XVI Semana da Educação e VI Simpósio de Pesquisa e Pós-graduacão em Educação do Departamento de Educação, 2015, Londrina (PR). ISBN: 978-85-7846-319-9, p 497 - 508.

MOZZATO, A. R.; GRZYBOVSKI, D. Análise de conteúdo como técnica de análise de dados qualitativos no campo da administração: potencial e desafios. RAC. Revista de Administração Contemporânea (Online), v. 15, p. 731-747, 2011.

OLIVEIRA, M. A. N.. (Re)Pensando A Formação De Professores Em Educação Ambiental. Revista Monografias Ambientais. Santa Maria, RS. Edição Especial. 2015, p. 08-16

RAUSCH, R. B.; FRANZ, M.. Contribuições do PIBID à formação inicial de professores na compreensão de licenciandos bolsistas. In: XI Congresso Nacional de Educação - EDUCERE, Curitiba: PUCPR, 2013. p. 12711-12727.

ROSA, K. N.S.; MATTO, L. Tem gente nova na escola: os benefícios do Pibid para o espaço escolar. Revista Veras, v. 3, p. 160, 2013.

SATO, M. Debatendo os desafios da educação ambiental. Revista Eletrônica do Mestrado em Educação Ambiental, Rio Grande, v. 1, n.FURG, p. R14-R33, 2001. 


\section{da Alta Paulista}

SOUZA, J.; Kantorski, L. P. ; Luís, M. A. V.. Análise documental e observação participante na pesquisa em saúde mental. Revista Baiana de Enfermagem, v. 25, p. 221-228, 2011

SPURI, E.; NASCIMENTO JUNIOR, A. F. . O desenho animado como ferramenta pedagógica: relato de uma experiência na disciplina de ensino de ciências. Revista de Ensino de Biologia da Associação Brasileira de Ensino de Biologia (SBEnBio), v. 7, p. 1662-1673, 2014.

TOZONI-REIS, M. F. C. Temas Ambientais como 'temas geradores': contribuições para uma metodologia educativa ambiental crítica, transformadora e emancipatória. Educar em Revista, Curitiba - PR, v. 27, p. 93-110, 2006.

VIVIAN, C. D.; PAULY, E. L. O uso do celular como recurso pedagógico na construção de um documentário intitulado: fala sério! Colabor@ (Curitiba), v. 7, p. 1-12, 2012. 